UNIVERSIDADE DE SÃO PAULO

INSTITUTO DE PSICOLOGIA

EINAT HAUZMAN

Estudo comparativo da densidade e topografia de neurônios de retinas de Philodryas olfersii e $P$. patagoniensis

(Serpentes, Colubridae) 
UNIVERSIDADE DE SÃO PAULO

INSTITUTO DE PSICOLOGIA CURSO DE PÓS-GRADUAÇÃO

\section{Estudo comparativo da densidade e topografia de neurônios de retinas de Philodryas olfersii e P. patagoniensis (Serpentes, Colubridae)}

Einat Hauzman

Orientadora: Prof ${ }^{\mathrm{a}}$ Dra Dora Fix Ventura

Dissertação apresentada ao Programa de Neurociências e Comportamento do Insituto de Psicologia da Universidade de São Paulo, como parte dos requisitos para a obtenção do grau de Mestre em Psicologia.

SÃO PAULO

2009 


\section{AUTORIZO A REPRODUÇÃO E DIVULGAÇÃO TOTAL OU PARCIAL DESTE TRABALHO, POR QUALQUER MEIO CONVENCIONAL OU ELETRÔNICO, PARA FINS DE ESTUDO E PESQUISA, DESDE QUE CITADA A FONTE.}

Catalogação na publicação

Serviço de Biblioteca e Documentação

Instituto de Psicologia da Universidade de São Paulo

Hauzman, Einat.

Estudo comparativo da densidade e topografia de neurônios de retinas de Philodryas olfersii e P. patagoniensis (Serpentes, Colubridae) / Einat Hauzman; orientadora Dora Selma Fix Ventura. -São Paulo, 2009.

$108 \mathrm{p}$.

Dissertação (Mestrado - Programa de Pós-Graduação em Psicologia. Área de Concentração: Neurociências e Comportamento) Instituto de Psicologia da Universidade de São Paulo.

1. Retina 2. Neurônios 3. Acuidade visual 4. Serpentes I. Título.

QP479 


\section{FOLHA DE APROVAÇÃO}

\section{Einat Hauzman}

"Estudo comparativo da densidade e topografia de neurônios de retinas de Philodryas olfersii e $P$. patagoniensis (Serpentes, Colubridae)"

Dissertação apresentada ao Instituto de Psicologia da Universidade de São Paulo, para obtenção do título de Mestrado.

Área de Concentração: Neurociências e Comportamento

Dissertação defendida e aprovada em:

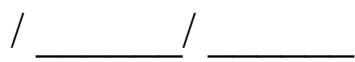

\section{BANCA EXAMINADORA}

Examinador(a) Assinatura

Nome

Instituição

Examinador(a) Assinatura

Nome

Instituição

Examinador(a) Assinatura

Nome

Instituição 
Aos meus pais, com carinho, por terem me trazido a este mundo e por tudo o que sempre fizeram por mim. Dedico este trabalho a vocês $e$ agradeço profundamente por todo amor, carinho e apoio que sempre me deram. Muito Obrigada! 


\section{AGRADECIMENTOS}

Agradeço a minha orientadora, Professora Dra. Dora Fix Ventura, pelos valiosos ensinamentos, pela orientação e por tornar possível a realização deste estudo, fornecendo todas as condições necessárias, físicas e intelectuais.

A querida amiga, Daniela Bonci, por todo o incentivo e apoio durante estes anos. Por trasmitir sua experiência no laboratório, com paciência e dedicação e pelo seu contagiante amor pela ciência.

A Sonia Grötzner, pela realização dos trabalhos de imunohistoquímica no Laboratório, que possibilitaram o uso dos materiais e protocolos em trabalhos subsequentes. Agradeço a importante contribuição na preparação de materiais histológicos e na discussão de metodologias.

A Selma Almeida-Santos, pela orientação e pelo exemplo de dedicação, desde o início de minha carreira acadêmica e estágio no Butantan. Pela orientação e incentivo inicial neste estudo.

Ao André e Soninha, pela contribuição prática e intelectual neste trabalho.

A Maritana pela preparação de material para a microscopia eletrônica de varredura.

Ao amigo Antonio (Toto), por toda ajuda e pela ótima idéia de iniciar o estudo comportamental com os filhotes de Philodryas.

Ao Rodrigo Scartozzoni pela ajuda, leitura e correções do projeto inicial.

Aos pesquisadores do Butantan, Otávio, Kiko e Hebert, pelo interesse neste trabalho e pelas contibuições e sugestões.

Ao Valdir, Antonio Carlos e Joãozinho, pelo fundamental auxílio com os animais, no Laboratório de Herpetologia.

Ao Laboratório de Herpetologia do Instituto Butantan, por fornecer os animais para este estudo. 
A Professora Dra. Dânia E. Hamassaki, por permitir o trabalho e o uso de materiais do Laboratório de Biologia Celular da Retina do ICB I, USP.

A todos os colegas do Laboratório de Psicofisiologia Sensorial e do Laboratório da Visão e aos colegas do Butantan, pelas ajudas e pelo agradável e bem humorado convívio.

As serpentes Philodryas.

A FAPESP, pela concessão da bolsa de mestrado e pelo apoio financeiro para a realização desta pesquisa.

A Laura e Tati, pela amizade e pelo carinho de sempre.

Aos meus pais pelo carinho e apoio, e aos meus familiares. Agradeço a tia Fani, por todo auxílio, desde o início da carreira acadêmica até agora. Muito obrigada!

Ao meu Mestre, Shri Swami Vyaghra Yogi, pelos ensinamentos e por todas as transformações proporcionadas. Dhanyavad!

Ao meu querido Pandit Kumar, por todo carinho, respeito, companheirismo e apoio! Dhanyavad! 
"Há uma grandeza simples no fato de considerar a vida, com as suas capacidades de desenvolvimento, como se tivesse sido originalmente insuflada na matéria sob uma ou poucas formas e no fato de que, enquanto este planeta girava em órbitas correspondentes a leis fixas, num ciclo de transformação em água e terra, foram substituindo-se uma após outra, através do processo de seleção gradual de mudanças infinitesimais, até chegarem a uma quantidade infinita de formas belíssimas e admiráveis."

Charles Darwin (A origem das espécies) 


\section{ÍNDICE GERAL}

1. Introdução

1.1 Serpentes: Diversidade e Adaptações....................................................................

1.1.1. Família Colubridae...........................................................................2

1.1.2. Descrição das espécies Philodryas olfersii e $P$. patagoniensis...................3

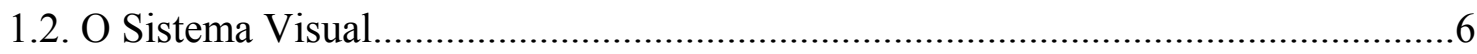

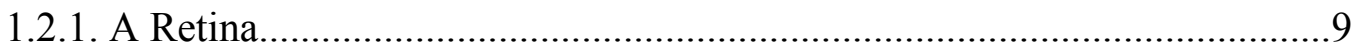

1.2.1.1. Fotorreceptores...................................................................11

1.2.1.2. Os Fotopigmentos e o Processamento Visual.............................15

1.2.1.3. Especializações da Retina........................................................19

1.2.2. Acuidade Visual......................................................................21

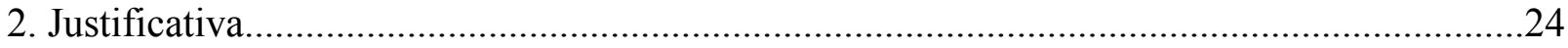

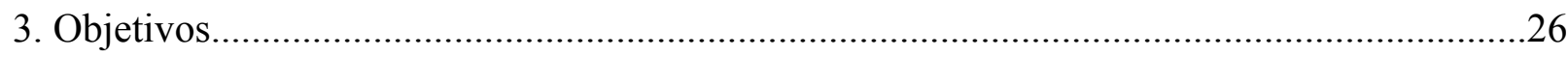

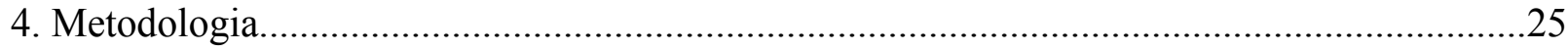

4.1 Procedimentos com os animais......................................................................27

4.2. Estudos morfológicos: histologia clássica e microscopia eletrônica de varredura...28

4.3. Imunohistoquímica........................................................................................29

4.3.1. Procedimentos imunohistoquímicos: retinas planas e cortes histológicos..26

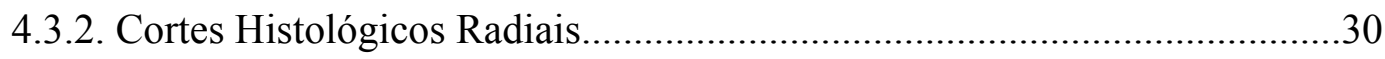

4.3.3. Montagens Planas (preparações íntegras das retinas)...............................34

4.4.Marcação de Células da CCG: Técnica de Nissl......................................................34

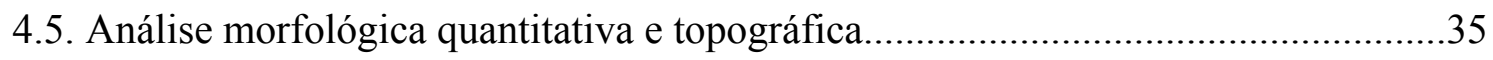

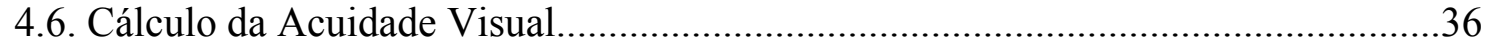

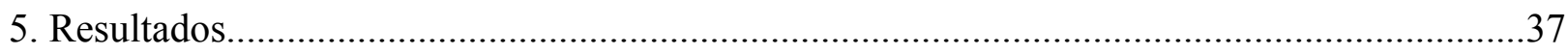

5.1. Análise morfológica: histologia clássica e microscopia eletrônica de varredura.......37

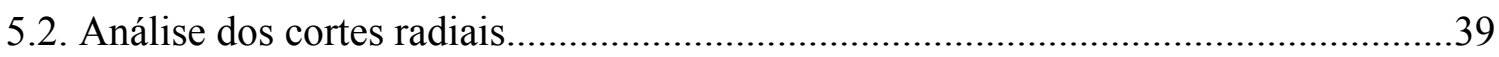

5.3. Análises topográficas e quantitativas: montagens planas.......................................42

5.3.1 População total de fotorreceptores.........................................................42

5.3.2. População de cones S..........................................................................48

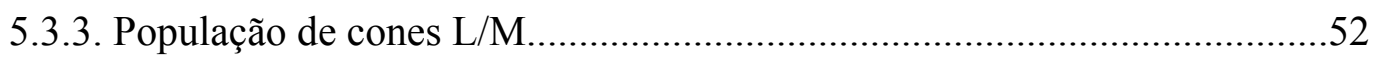

5.3.4. População de células da CCG................................................................56

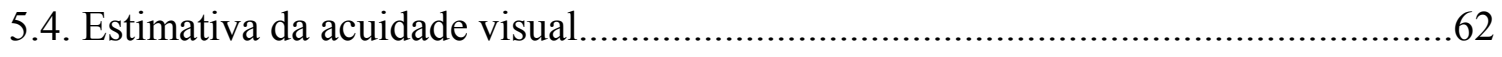

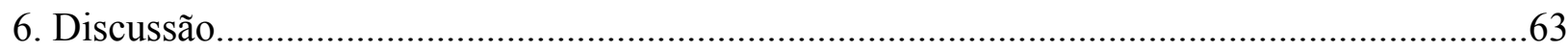

6.1. População de Fotorreceptores............................................................................63

6.2. Densidade e Topografia de Fotorreceptores...........................................................64

6.3. Densidade e Topografia de Células da CCG....................................................69

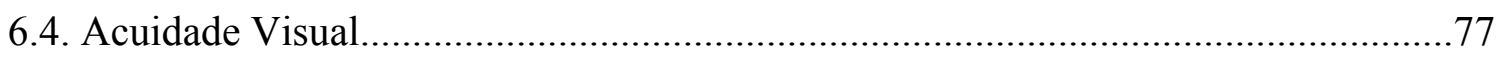

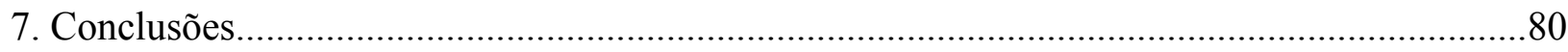

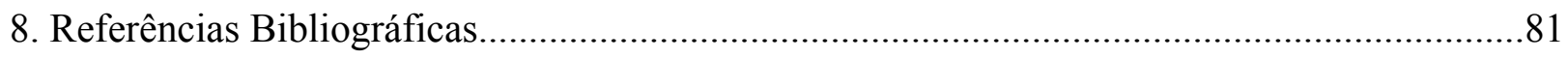

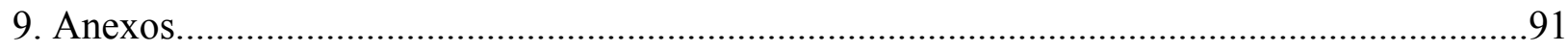




\section{ÍNDICE DE FIGURAS}

Figura 1. Philodryas patagoniensis (cobra parelheira) e Philodryas olfersii (cobra verde, boiubu) (Fotos: Otavio Marques)................................................................................ 3

Figura 2. Corte sagital de olho de serpente (Walls, 1942).......................................................

Figura 3. Anatomia funcional de olho de lagarto (A) e de serpente (B), ilustrando as principais diferenças entre os dois tipos. C, lagarto foca a imagem na retina contraindo os grandes músculos ciliares (bm, cm) ancorados aos ossículos da esclera (so), aplicando assim uma pressão na superfície lateral do cristalino (ln). D, serpentes focam a imagem na retina movendo o cristalino para frente, pelo aumento da pressão no vítreo (vi) devido a contração de músculos periféricos da íris (im). Abreviações: an, via anterior; bm, músculo ciliar de Brücke; cb, corpo ciliar; ch, coróide; cm, músculo ciliar de Crompton; cn, cônus papilar; co, córnea; el, pálpebra; fv, fóvea; id, músculo dilatador da íris; is, músculo do esfincter da íris; ln, lente; re, retina; sc, cartilagem da esclera; sl, esclera; sp, espectáculo; vi, humo vítreo; zf, fibras zonulares (Caprette, 2004). .8

Figura 4. Diagrama esquemático da retina de vertebrados (http://webvision.med.utah.edu/)......10

Figura 5. Representação de corte transversal de fotorreceptores da tartaruga Trachemys scripta. (A) cone simples, (B) cone duplo, (C) bastonete. Abreviações: se. segmento externo, go. gotícula de óleo, el. elipsóide, pa. parabolóide, ml. membrane limitante, mi. mióide, nu. núcleo, ts. terminal sináptico. A seta indica a direção da passagem da luz pela retina (Caprette, 2005).

Figura 6. Representaçao da morfológica de fotorreceptores de serpentes: (A) cones duplos, (B) cones simples grandes, (C) cones simples pequenos, (D) cones simples com mióide grande, (E) cones simples pequeno com mióide extremanente longo, $(\mathrm{F})$ cone duplo com mióide extremamente longo, $(\mathrm{G})$ bastonete longo e $(\mathrm{H})$ bastonete curto. Abreviações: se. segmento externo, el. elipsóide, ml, membrana limitante, nu. núcleo, ts. terminal sináptico, mi. mióide. A seta indica a direção que a luz passa pela retina (Caprette, 2005) .14

Figura 7. Pico de sensibilidade espetral dos três tipos de cones e bastonete da retina de primatas (Dowling, 1987). .16

Figura 8. Árvore filogenética para os pigmentos de vertebrados * (Yokoyama, 1997)..............18

Figura 9. A frequência espacial é a medida do número de ciclos formados por grau de ângulo visual. Cada ciclo é formado por uma barra preta e uma branca e a medida é dada em ciclos por grau (cpg). (a) um ciclo por grau; (b) dois ciclos por grau (imagem: http://webvision.med.utah.edu/). .22 
Figura 10. Imagem de corte transversal de olho de serpente (Walls, 1942). A barra vermelha representa a distância posterior nodal (PND), calculada como 50\% do tamanho do globo ocular nas serpentes estudadas. 36

Figura 11. Corte radial de retina da serpente Philodryas olfersii, corado com hematoxilinaeosina (técnica histológica e imagem: Sonia Grötzner). 37

Figura 8. Fotografias da camada de fotorreceptores de retina de $P$. olfersii (A e C) e $P$. patagoniensis (B e D), obtidas a partir de microscópio de varredura. cg cone simples grande; cp cone simples pequeno; cd cone duplo (técnica e imagens: Maritana Mela)...... 38

Figura 13. Cortes radiais de retinas de $P$. olfersii (a) e $P$. patagoniensis (b), imunomarcadas com o anticorpo RbaJH492 e reveladas com gtarb TRITC. $(\rightarrow)$ Marcação de segmentos externos de cones L/M. 40

Figura 14. Cortes radiais de retinas de $P$. olfersii (a) e $P$. patagoniensis (b), imunomarcadas com o anticorpo JH455 e revelado com gtarb TRITC. $(\rightarrow)$ Marcação de segmento externo de cone $\mathrm{S}$. Escala $=20 \mu \mathrm{m}$

Figura 15. Cortes radiais de retinas de $P$. olfersii (a) e $P$. patagoniensis (b), mostrando marcação inespecífica do anticorpo secundário biotinilado (gt $\alpha$-rb biot), em regiões da retina com biotina endógena: epitélio pigmentado (ep), região do elipsóide do segmento interno dos fotorreceptores (si) e membrana limitante externa (ml). Revelação feita com CY3 acoplado a estreptavidina.

Figura 16. Imagem utilizada para contagem do número total de fotorreceptores, a partir da marcação inespecífica do segmento interno (*), pelo anticorpo secundário (gtaRb). 42

Figura 17. Mapas topográficos dos fotorreceptores de três retinas de P. olfersii. a) Po 071205 OE; b) Po 071205 OD; c) Po 081106 OD. A representação está em gradiente de cinza. A estria visual estende-se ao longo do eixo rostro-caudal, e nota-se duas areae, com maior densidade celular na região caudal e a região central. $\mathrm{O}$ disco branco representa a saída do nervo óptico. 45

Figura 18. Perfil da variação de densidade de fotorreceptores ao longo do eixo dorso-ventral de três retinas de P. olfersii. (a) Po071205 OE, (b) Po081106 OD, (c) Po071205 OD...46

Figura 19. Mapas topográficos dos fotorreceptores de quatro retinas de $P$. patagoniensis. a) $\mathrm{Pp}$ 071107.02 OE; b) Pp070419 OE; c) 071107.01 OD; d) Pp 071205 OD. A representação está em gradiente de cinza. Nota-se uma maior densidade celular na região ventral da retina, com area visual na região rostro-ventral. O disco branco representa a saída do nervo óptico...

Figura 20. Imagem de retina plana de $P$. olfersii, incubada com JH455 e revelada com Cy3 acoplado a estreptavidina, utilizada para contagem do número de cones $\mathrm{S}$ e do número total de fotorreceptores. Observa-se os segmentos externos dos 
fotorreceptores imunomarcados $(\rightarrow)$ e os segmentos internos apresentando marcação inespecífica pelo Cy3

Figura 21. Médias e desvios padrão da densidade de fotorreceptores, dos cones $\mathrm{S}$ e dos cones $\mathrm{L} / \mathrm{M}$ nas retinas de $P$. olfersii e $P$. patagoniensis.

Figura 22. Mapas topográficos dos cones $\mathrm{S}$ de uma retina de P. olfersii (a) (retina Po 080221.02 OD) e de uma retina de $P$. patagoniensis (b) (retina Pp 071107.02 OE). A representação está em gradiente de cinza. Notam-se duas áreas de maior densidade celular, na região central e na região rostro-ventral em $P$. olfersii (a) e área de maior densidade celular na região ventral em $P$. patagoniensis (b). $\mathrm{O}$ disco branco representa a saída do nervo óptico. 51

Figura 23. Imagem de retina plana de $P$. olfersii, incubada com JH492 e revelada com Cy3 acoplado a estreptavidina, utilizada para contagem de cones $\mathrm{L} / \mathrm{M}$ e do número total de fotorreceptores. Observam-se os segmentos externos dos fotorreceptores imunomarcados $(\rightarrow)$ e os segmentos internos apresentando marcação inespecífica pelo Cy3. 52

Figura 24. Mapas topográficos dos cones L/M de uma retina de P. olfersii (a) (retina Po081106 OD) e uma retina de P. patagoniensis (b) (retina Pp 071205 OD). Em a) observa-se uma faixa visual acompanhando o eixo rostro-caudal, uma area centralis e uma area caudal. Em b) observa-se maior densidade celular na região ventral e uma area rostro-ventral. A representação está em gradiente de cinza. O disco branco representa a saída do nervo óptico. .55

Figura 25. Imagem de retina plana de $P$. olfersii, marcada com Nissl, mostrando os corpos celulares das células ganglionares $(\rightarrow)$ da $\mathrm{CCG}$ 56

Figura 26. Médias e desvios padrão da densidade de fotorreceptores e células da CCG das retinas de $P$. olfersii e $P$. patagoniensis. 57

Figura 27. Imagens do mesmo campo amostrado de uma retina de P. olfersii (Po081126 OE) marcada com técnica de Nissl. a) Camada de Fotorreceptores; b) Camada de Células Ganglionares (CCG). .58

Figura 28. a) Mapa topográfico das células da CCG de P. olfersii (Po081126 OE); b) Mapa topográfico do total de fotorreceptores de $P$. olfersii (Po071205 OD). As representações estão em gradiente de cinza. Nota-se uma faixa visual, uma area centralis e uma area caudal em a) e em b). O disco branco representa a saída do nervo óptico. .59

Figura 29. a) Mapa topográfico das células da CCG de P. patagoniensis (Pp081023.01 OD), com maior densidade celular na região central e rostral; b) Mapa topográfico do total de fotorreceptores de P. patagoniensis (Pp071205 OD), com maior densidade celular na região ventral e rostral. As representações estão em gradiente de cinza. O disco branco representa a saída do nervo óptico. .60 
Figura 30. Mapas topográficos da variação da proporção de fotorreceptores e de células da CCG em retina de $P$. olfersii (Po 081126 OE) (a) e retina de $P$. patagoniensis (Pp081023.01 OE) (b). As representações estão em gradiente de violeta (1:1), onde há maior quantidade de células ganglionares, ao amarelo (1:3), com maior densidade de fotorreceptores e menor densidade de ganglionares. O disco branco representa a saída do nervo óptico. 61

Figura 31. Árvore filogenética das opsinas para representantes do grupo dos vertebrados (Jacobs \& Rowe, 2004).

Figura 32. Mapas topográficos dos fotorreceptores de $P$. olfersii (a) e $P$. patagoniensis (b), mostrando as diferentes regiões de especialização das retinas com aumento da densidade celular.

Figura 33. Imagem da camada de células ganglionares (CCG) de retina de $P$. olfersii (Po081106OE), marcada com Nissl. Abaixo: células contadas marcadas em vermelho; as células com núcleo ovóide e citoplasma denso não foram contadas (possíveis células amácrinas deslocadas). .71

Figura 34. Foto de cabeça de $P$. patagoniensis (acima) e $P$. olfersii. .76 


\section{ÍNDICE DE TABELAS}

Tabela 9. Diferentes anticorpos primários testados nos cortes radiais das retinas de Philodryas olfersii e $P$. patagoniensis.

Tabela 1. Densidade média e população total dos fotorreceptores das retinas de $P$. olfersii e $P$. patagoniensis......

Tabela 2. Medidas de cada serpente e valores de densidade dos fotorreceptores das retinas de Philodryas patagoniensis. $\mathrm{CRC}=$ comprimento rostro cloacal; $\mathrm{CC}=$ comprimento caudal; $\mathrm{m}=$ massa $(\mathrm{g})$. .43

Tabela 3. Medidas de cada serpente e valores de densidade dos fotorreceptores das retinas de Philodryas olfersii. $\mathrm{CRC}=$ comprimento rostro cloacal; $\mathrm{CC}=$ comprimento caudal; $\mathrm{m}=$ massa $(\mathrm{g})$. 44

Tabela 4. Densidade média e população total dos cones $\mathrm{S}$ de $P$. olfersii e $P$. patagoniensis.......50

Tabela 5. Valores de densidade de cones $\mathrm{S}$ das retinas de $P$. olfersii e $P$. patagoniensis. .50

Tabela 6. Densidade média e população total dos cones $\mathrm{L} / \mathrm{M}$ das retinas de $P$. olfersii e $P$. patagoniensis...... 53

Tabela 7. Valores de densidade de cones $\mathrm{L} / \mathrm{M}$ nas retinas de $P$. olfersii e $P$. patagoniensis... .53

Tabela 8. Densidade média e população total das células da CCG de $P$. olfersii e $P$. patagoniensis...... .58

Tabela 9. Valores calculados da Acuidade Visual para cada retina de $P$. olfersii e $P$. patagoniensis; $\mathrm{PND}=$ distância posterior nodal calculada para cada olho; $\mathrm{d}=\mathrm{um}$ grau na retina; $\mathrm{S}=$ medida de espaçamento intracelular entre as células; $\mathrm{v}=$ frequência espacial máxima; cpg = resolução espacial em ciclos/grau. .62

Tabela 10. Cálculos comparativos da acuidade visual. Quando possível, foi incluido para cada espécie tanto a acuidade estimada a partir do tamaho do olho e da densidade de células ganglionares, quanto a acuidade visual determinada comportamentalmente (Pettigrew \& Manger, 2008). .78 


\section{RESUMO}

As serpentes são um grupo altamente diversificado, encontradas em praticamente todas as regiões do planeta, ocupando diferentes ambientes. Sua diversidade adaptativa indica a grande variabilidade dos órgãos sensoriais, adaptados ao hábitat e hábitos de cada espécie. Estudos sobre o sistema visual das serpentes são escassos e tem grande importância na compreensão de caracteres ecológicos, comportamentais e filogenéticos. Nos vertebrados as informações visuais são projetadas na retina e inicialmente processadas nessa camada neural, antes do processamento que ocorre no sistema nervoso central. Os tipos de células encontradas na retina, bem como sua densidade e distribuição variam entre as espécies e determinam especializações do sistema visual. Neste trabalho foi feita uma quantificaçao comparativa de fotorreceptores e neurônios da camada de células ganglionares (CCG) de duas espécies de serpentes colubrídeas diurnas, Philodryas olfersii e $P$. patagoniensis. Para tanto foram utilizadas técnicas de imunohistoquímica de opsinas e de marcação de Nissl. Serpentes adultas obtidas no Instituto Butantan foram anestesiadas com tiopental $(30 \mathrm{mg} / \mathrm{kg})$ e sacrificadas com $\mathrm{CO}_{2}$. Os olhos foram enucleados e as retinas dissecadas e fixadas em paraformaldeido $4 \%$. Um olho de cada serpente foi utilizado para fazer cortes radiais e testar diferentes tipos e concentrações de anticorpos. Para a preparação das retinas planas foram utilizados o anticorpo $\mathrm{JH} 455$, produzido em coelhos contra opsinas sensíveis aos comprimentos de onda curto de humanos (cones S) e o anticorpo JH492, produzido em coelhos contra opsinas sensíveis aos comprimentos de onda médio e longo de humanos (cones L/M). Foi utilizado anticorpo secundário biotinilado (gt $\alpha$-rb biot) e a revelação feita com estreptavidina acoplada a molécula florescente CY3. Os cortes radiais e as retinas planas foram observadas em microscópio fluorescente equipado com câmara digital conectada a microcomputador dotado de programa para captura de imagens. A partir de imagens da retina obtidas com espaçamento mínimo de $0,5 \mathrm{~mm}$ foram feitas as contagens das células e os mapas de isodensidade celular. A densidade média dos fotorreceptores foi semelhante nas duas espécies $\left(11.183,1 \pm 1.107,4\right.$ células $/ \mathrm{mm}^{2}$ em $P$. olfersii e $11.531,2 \pm 1.054,9$ células $/ \mathrm{mm}^{2}$ em $P$. patagoniensis), assim como a proporção dos diferentes tipos de cones (3\% cones $\mathrm{S}$ e $83 \%$ cones L/M em $P$. olfersii, e $5 \%$ cones $\mathrm{S}$ e $85 \%$ cones L/M em P. patagoniensis). As densidades de células da CCG também foram semelhantes $\left(10.117,5 \pm 1.026\right.$ células $/ \mathrm{mm}^{2}$ em $P$. olfersii e $9.834,9 \pm 2.772,2$ células $/ \mathrm{mm}^{2}$ em $P$. patagoniensis). Entretanto, os mapas de isodensidade mostraram diferentes regiões de especialização. $P$. olfersii apresentou uma faixa horizontal e duas areas centralis de maior densidade celular, uma na região central e uma na região caudal, indicando a melhor acuidade visual nos campos de visão frontal e lateral, o que possivelmente auxilia na locomoção e forrageamento no extrato arbóreo. P. patagoniensis apresentou maior densidade celular na região ventral e rostral, indicando a maior acuidade no campo visual superior e posterior, auxiliando na percepção da aproximação de predadores e animais maiores, importante para a sobrevivência de serpentes terrestres e possivelmente para a percepção de presas localizadas em estrato arbustivo. 


\section{ABSTRACT}

Snakes are a diversified group found in almost all regions of the planet, occupying different habitats, with exception to Polar Regions, a few islands and the deeper ocean waters. Its diversity indicates the high variability of sensory organs, which are adapted to the habits and habitats of each species. Studies about snake's visual system are scarce and have a great importance for the understanding of their ecology, behavior and phylogeny. In vertebrates the visual information is projected in the retina and initially processed in this neural tissue, before its processing in the central nervous system. The different kinds of cells present, as well as its density and distribution in the retina, vary between species and determinate specializations of the visual system. In this study we compared the density and distribution of photoreceptors and neurons of the ganglion cells layer (GCL) of two diurnal colubridae snakes, the arboreal Philodryas olfersii and the terrestrial P. patagoniensis, with opsins immunohistochemistry and Nissl staining. Adult snakes obtained in Instituto Butantan were anesthetized with thiopental $(30 \mathrm{mg} / \mathrm{Kg})$ and the euthanasia was done with $\mathrm{CO}_{2}$. The eyes were enucleated and the retinas dissected and fixed in paraformaldeid $4 \%$. One eye of each species was sectioned to test different antibodies and the counting for the determination of topographic distribution of density was made in flattened wholemount retinas. In the wholemounts retinas it was utilized the antibodies JH455 produced in rabbit against human $\mathrm{S}$ cone opsins and $\mathrm{JH} 492$ produced in rabbit against human $\mathrm{L} / \mathrm{M}$ cone opsins. The photoreceptors density were similar in the two species $\left(11,1831 \pm 1,107.4 \mathrm{cells} / \mathrm{mm}^{2}\right.$ in P. olfersii and 11,531.2 $\pm 1,054.9$ cells $/ \mathrm{mm}^{2}$ in P. patagoniensis), as well as the proportion of the different types of cells $(3 \% \mathrm{~S}$ cones and $83 \% \mathrm{~L} / \mathrm{M}$ cones in $P$. olfersii, and $5 \% \mathrm{~S}$ cones and $85 \% \mathrm{~L} / \mathrm{M}$ cones in $P$. patagoniensis $)$. The GCL cells density were also similar $(10,117.5 \pm 1,026$ cells $/ \mathrm{mm}^{2}$ in $P$. olfersii and $9,834.9 \pm 2,772.2 \mathrm{cells} / \mathrm{mm}^{2}$ in $P$. patagoniensis). However, the isodensity maps showed different specializations regions. $P$. olfersii showed a horizontal streak and two areae (area centralis) with higher density, in the central and in the caudal regions, indicating a better visual acuity in the lateral and in the frontal visual field, what is possibly very important for locomotion and searching for preys (foraging) in the arboreal layer. $P$. patagoniensis showed a higher cell density in the ventral and rostral regions of the retina, indicating a better visual acuity in the superior and posterior visual field, what is important to perceive the approaching of predators and terrestrial animals and preys located in underbushes above the snake. 


\section{INTRODUÇÃO}

\subsection{Serpentes: Diversidades e Adaptações}

As serpentes são um grupo altamente diverso encontrado em praticamente todas as porções da biosfera, com exceção dos pólos, algumas ilhas e fundos oceânicos (Lillywhite \& Henderson, 1993). A grande diversidade do grupo, composto por cerca de 2900 espécies, distribuídas em 449 gêneros e 18 famílias, pode ser explicada pela ocorrência de uma série de radiações adaptativas (Cadle, 1987; McDowell, 1987; Ford \& Burhard, 1993).

As serpentes atuais podem ser classificadas em dois grandes grupos. O grupo Scolecophidia, das chamadas cobras-cegas, composto por serpentes pequenas, fossórias e com olhos reduzidos e o grupo Aletinophidia, composto pelas demais serpentes, com grande número de famílias e diversidade de adaptações (ver classificação abaixo).

\section{Classificação das serpentes}

Reino: Animalia

Filo: Chordata

Classe: Reptilia

Ordem: Squamata

Subordem: Ofidia

Superfamílias: $\left\{\begin{array}{l}\text { Scholecophidia } \\ \text { Alethinophidia }\end{array}\right.$

Noturnas ou diurnas, as serpentes estão presentes em praticamente todos os nichos ecológicos, podendo ser terrestres, aquáticas ou semi-aquáticas, de água doce ou marinhas. No hábitat terrestre podem ocupar ambientes fossoriais, criptozóicos (tocas, galerias ou folhiços no 
solo), terrícolas e arborícolas (Greene, 1997). Apresentam dieta variada, empregando diferentes estratégias de caça para a captura de suas presas, sendo algumas forrageadoras ativas, enquanto que outras caçam por espreita (Mushinky, 1987).

O sucesso evolutivo deste grupo está certamente relacionado ao alto grau de desenvolvimento de alguns órgãos sensoriais (Ford \& Burghardt, 1993). A variedade de adaptações anatômicas dos olhos das serpentes demonstra como os fatores ambientais influenciam na estrutura ocular e sua função (Walls, 1942). Os diferentes hábitats e ambientes ocupados pelas serpentes diferem na qualidade espectral da luz, o que deve influenciar nos padrões comportamentais relacionados à demanda pelo sistema visual (Ford \& Burghardt, 1993).

\subsubsection{Família Colubridae}

A família Colubridae é a mais diversa, com cerca de 1690 espécies, representando aproximadamente 65\% das serpentes conhecidas (Underwood, 1967; Kraus \& Brown, 1998; Gravlund, 2001). São encontradas em todos os continentes, com exceção da Nova Zelândia e regiões polares (Rage, 1987). Com grande diversidade morfológica e adaptativa, estão incluídas nesta família serpentes de hábitos noturnos e diurnos, fossoriais, aquáticas ou semiaquáticas, terrícolas e arborícolas.

As serpentes desta família são consideradas não peçonhentas ou semi-peçonhentas, dependendo da espécie e do tipo de dentição apresentada, que pode ser áglifa (sem presas diferenciadas) ou opistóglifa (com dentes diferenciados, localizados no fundo da boca). As espécies empregam diferentes estratégias de caça, como forrageamento ativo ou caça por espreita. As formas de subjugação das presas podem ser por mordida ou enrodilhamento em torno da presa. 